\author{
Asian Journal of \\ Medical and Biological Research \\ ISSN 2411-4472 (Print) 2412-5571 (Online) \\ www.ebupress.com/journal/ajmbr
}

\title{
Article \\ Disease burden and associated factors of rotavirus infection in calves in south- eastern part of Bangladesh
}

Shama Ranjan Barua ${ }^{*}$, Tofazzal Md. Rakib ${ }^{3}$, Mohammad Mahbubur Rahman ${ }^{3}$, Sarina Selleck ${ }^{2}$, Md. Masuduzzaman $^{3}$, AMAM Zonaed Siddiki ${ }^{3}$, Mohammad Alamgir Hossain ${ }^{3}$ and Sharmin Chowdhury ${ }^{3}$

${ }^{1}$ Department of Livestock Services, Ministry of Fisheries and Livestock, Government of the People's Republic of Bangladesh

${ }^{2}$ University of Vermont, Burlington, VT 05405, USA

${ }^{3}$ Department of Pathology and Parasitology, Faculty of Veterinary Medicine, Chittagong Veterinary and Animal Sciences University, Khulshi, Chittagong - 4225, Bangladesh

*Corresponding author: Shama Ranjan Barua, Upazila Livestock Officer, Rajasthali, Rangamati, Bangladesh. Phone: +8801818737220; E-mail: samardvm27@gmail.com

Received: 03 June 2019/Accepted: 27 June 2019/ Published: 30 June 2019

\begin{abstract}
Rotaviruses are considered as a major cause in the etiology of diarrhea in young calves worldwide and it causes calf morbidity, mortality and substantial economic losses in the dairy industry. This study reports the determination of the disease burden and first evaluation of associated risk factors of rotavirus infection in calves in Bangladesh. A cross sectional survey was carried out for the approximation of prevalence and associated risk factors of rotavirus infection in neonatal calves in South-eastern part of Bangladesh. From July 2015 to May 2016 a total of 411 calves under the age of 6 weeks from 210 dairy farms were selected using probability sampling scheme. Rotavirus infection was diagnosed from calf fecal samples using a commercial ELISA kit. Different farm and calf level factors were tested by mixed effect multivariable logistic regression models to differentiate factors significantly contributing to the high burden of rotavirus infection in calves in the study area. Overall prevalence of rotavirus in calf feces, irrespective of diarrheic and non-diarrheic, was estimated as $5.11 \%$. Among the hypothesized risk factors, samples from winter season showed higher odds of having the infection compared to summer $(\mathrm{OR}=6.04)$. Likewise, higher odds ratios were observed in: $>3$ weeks of age group compared to $\leq 3$ weeks $(\mathrm{OR}=2.87)$, taking of first colostrums after 30 minutes to 2 hours of birth in contrast to within 30 minutes $(\mathrm{OR}=13.92)$, and finally, calves from $3^{\text {rd }}$ to $4^{\text {th }}$ parity compared to $1^{\text {st }}$ to $2^{\text {nd }}$ parity $(\mathrm{OR}=6.79)$. Enteric diseases are a vital health problem in calves that interrupts production benefits with reduced weight gain and increased mortality rates and moreover it has potential to spread. Therefore, it is imperative to determine the disease burden and responsible risk factors to execute effective preventive measures among the population at higher risk.
\end{abstract}

Keywords: calves; prevalence; risk factors; rotavirus

\section{Introduction}

Diarrhea is one of the leading causes of calf mortality, morbidity and economic losses in the dairy industry, especially in developing countries. Current understanding is that calves are affected by diarrhea more often at an early stage of the lactation period and it involves a complex multifactorial condition constituting animal, environmental, nutritional and infectious agents (Garcia et al., 2000; Kyle, 2007; Al-Robaiee and Al-Farwachi, 2013). Rotavirus, Coronavirus, Cryptosporidium and Escherichia coli are the potential enteropathogens responsible for $75 \%$ to $95 \%$ of all neonatal calf diarrhea worldwide (Tzipori, 1985; Garcia et al., 2000; Suresh et al., 2011). Among these all causal agents, rotavirus infection is considered most detrimental as it is transferable between humans and animals and leads to severe enteric illness in humans, young animals and 
birds. (Nataraju et al., 2009; Martella et al., 2010) and rotavirus alone generate diarrhea in around 27-36\% newborn calves (Chauhan and Singh, 1996).

Rotavirus is the member of the family Reoviridae- the non-enveloped viruses contain a segmented, doublestranded RNA genome. There are eight distinct groups or serogroups of rotaviruses named as A to $\mathrm{H}$, based on antigenic property of the VP6 protein; among these, rotavirus A (RVA) shows more diversity (Matthijnssens and Desselberger, 2012; Anh et al., 2014). Groups A to C are pathogenic for humans as well as animal species, where as groups $\mathrm{D}$ to $\mathrm{H}$ are responsible for infection in avian species only (Dhama et al., 2009; Matthijnssens $e t$ al., 2012; Anh et al., 2014; Gachanja et al., 2015).

Rotavirus is environmentally distributed worldwide and was extensively studied (Straw, 2006; Zimmerman et al., 2006). Prevalence of rotavirus was estimated ranging from $11.81 \%$ to $26.8 \%$ in different parts of the neighboring country India (Pantnagar and Dehradun, Northern india, Punjab, Madhya Pradesh and Kolkata) among diarrheic calves (Jindal et al., 2000; Nataraju et al., 2009; Basera et al., 2010; Malik et al., 2013). In different European countries rotavirus infection was widely examined. In Sweden between 1993 and 2006 estimated prevalence was 24-47\% (De Verd Er, 2006), 42\% in diarrheal outbreak in the UK (Reynolds et al., 1986), 37 to 47.4\% in France (De Rycke et al., 1986; Bendali et al., 1999). In Bangladesh, prevalence of rotavirus infection in calf feces varied from 0 to $7 \%$ in previous studies (Samad and Ahmed, 1990; Selim et al., 1991; Alam et al., 2013).

Many factors were found to be responsible for influencing the severity and pathogenesis of rotavirus infection in calves. Factors like intake of colostrums, age and health status of the calves, immune status of the dam, degree of exposure and virulence of virus, and the presence of secondary pathogens were revealed as key parameters (Chauhan and Singh, 1996; Steele et al., 2004; Dhama et al., 2009). Epidemiological studies revealed that calves are more vulnerable to rotavirus infection at 1-3 weeks of age and age is demonstrated as the most important influencing factor (Radostitis et al., 2000; Dhama et al., 2009). Colostrums contain specific antirotaviral antibodies that prevent infection and diarrhea at an early age, while it declines rapidly, and about three days post partum the concentration becomes non-protective (Kyle, 2007). The results of several investigations pointed out that mixed infections are more common in calves at an early age than infections with single pathogens and rotavirus infection usually occurs in combination with E. coli or corona virus, might lead to high mortality (Radostitis et al., 2000; Dhama et al., 2009). Furthermore, rotavirus was frequently found in calves kept in large groups (Kyle, 2007). However, the morbidity rate varies from herd to herd and from one year to another; the survival of rotavirus in air and on surfaces was found to be influenced by the air humidity (Radostitis et al., 2000). Additional factors like dehydration, unhygienic surroundings, variations in temperature or chilling during winter and high population density in farms might enhance the disease condition (Chauhan and Singh, 1996; Dhama et al., 2009)

Although shedding of rotavirus is known to be unexceptional in dairy calves in developing countries, little has been published on prevalence and possible risk factors for the infection in dairy calves in Bangladesh. Taking into account the zoonotic potential of rotaviral diarrhea in calves and its economic impact on dairy industry of Bangladesh, we conducted a comprehensive study using pertinent diagnostic protocols, standard study design and advanced statistical analyzing tools for a precise understanding of disease burden and risk factors. In Bangladesh, few studies concerning bacterial and parasitic neonatal calf diarrhea has been executed, but published study concerning virus is substantially low; no risk factor study was retrieved on rotaviral infection. To the best of our knowledge, this is the first comprehensive research in Bangladesh to evaluate the associated factors of rotavirus infection in calves. Moreover, it is unknown whether risk factors identified by previous works done elsewhere (in abroad), are associated with the risk of infection and diarrhea in the study area. Nevertheless, diagnosis and treatment of rotaviral diarrhea in claves involves cost; could be a concern for small holding dairy farms abundant in the study area (Chowdhury et al., 2017). Knowing the risk factors might assist them in preventing the disease prior infection. Therefore, this study was carried out with the objective of estimating prevalence and identifying potential calf-level and herd-level risk factors for rotaviral diarrhea among dairy calves less than 6 weeks of age so that possible control measures can be established to reduce the calf mortality and zoonotic infection potential.

\section{Materials and Methods}

\subsection{Study area and period}

This study was conducted in three different distinct geographic areas situated in the south-eastern part of Bangladesh under Chittagong division; hilly, coast and plain land. Administratively Bangladesh is divided into divisions (largest administrative area). Divisions are further divided into districts and districts into sub districts. Chittagong metropolitan and Patiya upazilla (sub-district) were selected as plain land under Chittagong district, 
Rangamati sadar and Kowkhali upazilla were chosen as hilly area under Rangamati district and Chakaria and Pakua upazilla as coastal area under the district of Cox's bazar using probability sampling. The present study was conducted from July, 2015 through May, 2016.

\subsection{Sampling strategy and study population}

We followed a multi stage (three stages) random sampling strategy to select study subjects. Our study area was Chittagong division and study unit was individual calf. A list of all districts and sub districts under Chittagong division was collected from Bangladesh Bureau of Statistics. Districts under the division were divided into 3 regions; hilly, coast and plain. At first stage of sampling, one district from each geographical region was selected using simple random sampling; Chittagong district was selected purposively though. At second stage, two sub districts from each selected districts were selected using random sampling. At the third stage, to select farms under sub districts, we collected the sampling frame created by the Sub-project Manager Team under the project HEQEP CP: 3220, Chittagong Veterinary and Animal Sciences University (CVASU), Chittagong, Bangladesh for the dairy farms within Chittagong metropolitan area and Patiya. For other sub districts no sampling frame was available and convenience sampling strategy was followed to select farms. However, during convenience sampling, discussions about the locations and variety of farms were discussed thoroughly with the local practitioners to include as much as variation possible in to the study from those areas. Where sampling frame existed, a random number table was used to draw farms from the sampling frame. After selection of dairy farms, all calves less than 6 weeks of age within the selected farms were picked for sample collection. Our targeted sample size was 395 calves. Sample size was calculated considering 50\% estimated prevalence (due to unavailability of reliable estimate at the study area) and 5\% allowable error. We selected 101 farms from Chittagong district, 65 farms from Cox's Bazar district and 43 farms from Rangamati district. After completion of sampling procedure we ended up with 411 samples from diarrheic and non diarrheic calves within the mentioned age group.

\subsection{Study design and data collection tool}

We followed a cross sectional survey design to collect data from the selected farms and calves. A questionnaire (for data collection) was developed before the initiation of the survey. A comprehensive literature review was done before formulating the questionnaire to congregate information about potential risk factors for rotaviral infection in calves. The draft questionnaire was discussed with selected practitioners working on calf diarrhea and to epidemiologist experienced with risk factor analysis. The questionnaire was corrected according to the suggestions of the experts. A pilot study was done including a small number of farms around the center of the research station (CVASU, Bangladesh) and was amended accordingly where necessary.

\subsection{Specimen collection}

Fecal samples were collected from rectum using a disposable latex glove and in some cases the middle layer of a fresh voiding on the floor was collected when rectum was empty. All standard precautionary measures were taken in consideration during sample collection. All the samples were collected separately in a sterilized plastic container and labeled properly with the identification number, type and age of animal, location and time of sample collection etc. and transported carefully in an ice box to the laboratory preferably within 24 hours of collection.

\subsection{Sample processing}

Laboratory analysis was done at the clinical pathology laboratory, Department of Pathology and Parasitology, CVASU, Chittagong on the day of collection. Fecal samples were divided into $2 \mathrm{ml}$ aliquots and refrigerated. One aliquot was stored at $4^{\circ} \mathrm{C}$ until processing for the commercial ELISA test kits at the laboratory. The remaining $2 \mathrm{ml}$ aliquots of feces were stored at $-70^{\circ} \mathrm{C}$ for further testing, if required.

\subsection{ELISA testing}

A total of 411 fecal samples were tested using a commercial ELISA kit for rotavirus (Antigenic ELISA kit for detection of rotavirus, Bio-X® Diagnostics; Jemelle, Belgium) according to the instruction of the manufacturer. Briefly, $100 \mu \mathrm{l}$ of diluted samples (50 $\mu 1$ of dilution buffer and then $50 \mu 1$ of undiluted feces) were plated into the wells of a microplate coated with the appropriate antibody. The plate was held at room temperature (approximately $21^{\circ} \mathrm{C}$ ) for $60 \mathrm{~min}$ and then washed manually using the washing solution provided. Then $100 \mu \mathrm{l}$ of conjugate solution was added to the wells for each sample and the plate was held at room temperature (approximately $21^{\circ} \mathrm{C}$ ) for $60 \mathrm{~min}$. After a final wash, tetramethylbenzidine (TMB) substrate was added to each 
well and the plate was incubated at room temperature for an additional $10 \mathrm{~min}$. Then $50 \mu \mathrm{l}$ of stop solution was added and the optical densities were measured at $450 \mathrm{~nm}$ using an ELISA plate reader (Labsystems Multiscan Biochromatic; Labsystems, Basingstoke, UK). The ELISA reader was used to transfer optical density data, according to the manufacturer's instruction. Positive and negative reaction in ELISA was decided based on color changes after adding stop solution as well as calculating the optical density value. Blue color changed to yellow after adding stop solution was recognized as positive and optical density value was $>1.088$ for positive and $<1.088$ for negative to rotavirus.

\subsection{Data management}

The dependent variable was the calf-level rotavirus test result in ELISA (positive, negative).We started with 39 variables from the questionnaire based on preceding understanding hypothesized to be linked with rotaviral infection in calves in different countries. A farm level variable was defined as a variable with homogenous value for all calves in a farm across the study period. The variable "season" was extracted from the sample collection date. In Bangladesh, though officially there are six seasons, due to minimal variation in temperature and other environmental factors across different seasons, seasons can be divided broadly into 2 main types. For the present study we divided two seasons as: (1) winter $=$ October, November, December, January, February, (2) summer = March, April, May, June, July, August, September. The continuous variables (herd size, total area of the farm, population density, age, body weight) were inspected for linearity and to do so they were categorized into 4 categories using quartiles as cut-off values. Logistic regression analysis was executed employing the categorized variables and assessed if there was a growing (or declining) tendency in the parameter estimates. If there was a linear grow or decline in the parameter estimates, we concluded linearity in the continuous variable. If nonlinearity was notified in the continuous variables, we included the variable as categorical variable in to the model using quartile to categorize it. Some continuous and quantitative variables were categorized corresponding to prior perception, for example, age of the calves were divided in to 2 levels; $\leq 3$ weeks and $>3$ weeks, parity in 3 levels; $1-2,3-4,>4$. Some variables were not included in to the analysis due to either less variation (e.g. grazing, loose motion in family members of the farm owner) or too much variation (species of other animals rearing within the same premise). The later one was further categorized as presence or absence of other animals within the farm regardless species and included in to the analysis.

\subsection{Statistical analysis}

Throughout the study period, 411 calf test results from 210 dairy farms were incorporated into the analysis. Spearman correlation coefficient was used to assess correlation between the 39 independent variables incorporated in to the study. Variables with a Spearman correlation coefficient above 0.4 were judged correlated. Continuous variables were plotted using scatter plots for visual evaluation of correlation. During the selection procedure, depending on existing knowledge, biological plausibility of correlation between variables was also judged. Finally, univariable analysis was performed for the chosen explanatory variables and those having $P$-value $\leq 0.1$ were selected for multivariable analysis. Descriptive analysis was accomplished by modes of frequency $(\mathrm{N}, \%)$ of positive and negative calf level test results overall and stratified by selected explanatory variables.

\subsection{Multivariable analysis}

Multivariable logistic regression analyses with random effects (using a generalized linear mixed model) were conducted to assess the influence of different likely explanatory variables (categorical/categorized and binary) on the binary outcome variable: rotavirus test status of the calf. To approximate the region and farm level random effects, a simple random effect model was executed initially. Hierarchical level (farm or calf) of the variables were maintained during modeling. A backward elimination strategy was followed by deleting one variable at a time with the highest $P$-value. After deletion of one variable from the model, the coefficient of significant variables was inspected for any change in the estimates; the variable was retained in to the model for more than $20 \%$ change, to account for its confounding influence. All variables with a $P$-value $<0.05$ were incorporated into the final model. Interactions between all explanatory variables ( 2 ways) were checked in the final model.

Data management and analysis were performed using SAS version 9.2 (SAS Institute Inc., Cary, NC). For descriptive analysis, the procedures PROC FREQ, PROC CORR, PROC GPLOT, and PROC UNIVARIATE were used, and for the univariable and multivariable analyses, PROC GLIMMIX commands were used. 


\section{Results}

In total, 411 diarrheic and non-diarrheic fecal samples and their relevant herd and farm level information were collected and analyzed to determine the prevalence of rotavirus infection in calves in south-eastern region of Bangladesh.

Correlation was observed between 'total farm area' and 'herd size'. 'Population density' was correlated with both 'total farm area' and 'herd size'. Due to correlation, 'total farm area' and 'population density' were not included in to the analysis. 'Age of the calf' and 'body weight' was correlated at borderline (correlation coefficient 0.4 ) as continuous variable and we decided to use both variables as categorical variable in to the model; also because nonlinearity was observed with outcome variable. Altogether, 11 variables were statistically significant at a level of 0.1 in the univariable analysis and included in the initial multivariable logistic regression model (Table 1).

The overall prevalence of rotaviral infection in calves less than 6 weeks of age was estimated as $5.11 \%$ (21/411). Higher prevalence (7.14\%) was observed in calves with more than 3 weeks of age compared to calves less than 3 weeks of age (prevalence $=3.26 \%$ ). Winter had a higher prevalence $(9.59 \%)$ compared to summer months $(4.14 \%)$. Only one calf $(0.89 \%)$ without the history of calf scour was notified positive to rotavirus compared to recovered (5.77\%) calves and calves currently having diarrhea (7.18\%). A higher prevalence (9.88\%) was observed among calves those were given colostrums after 30 minutes to 2 hours compared to calves given colostrums within 30 minutes of birth (1.81\%). See Table 1 for stratified prevalence of other variables.

In multivariable analysis, five variables (season, age, first colostrums after birth, parity and maximum age difference between calves within a pen) were found statistically significant (Table 2). It was revealed that, in winter season, the odds of having rotavirus infection among calves less than 6 weeks of age was 6 times higher compared to summer months (baseline). When calves become aged $>3$ weeks, they become more susceptible $(\mathrm{OR}=2.87)$ to rota viral infection. Feeding colostrums to calves as early as within 30 minutes of birth (baseline) was proven better over feeding it after 30 minutes of birth $(\mathrm{OR}=13.92)$. Calves with parity 3-4 showed a significantly higher chance $(\mathrm{OR}=6.79)$ of having the infection compared to other parity categories. When the maximum age variation within a calf pen was $<4$ weeks, calves were more prone to positive infection $(\mathrm{OR}=12.27)$.

Random effect of region was not found noticeable (estimate $=0.083$ ) in the simple initial random effect model and was removed from further analysis accordingly. Random effect of farm was estimated as 0.354 . Interactions between explanatory variables were not significant. 
Asian J. Med. Biol. Res. 2019, 5 (2)

Table 1. Distribution of variables identified as significant $(\leq 0.1)$ in the univariable analysis as risk factor for Rota viral infection in south-eastern part of Bangladesh from June 2015 to May 2016.

\begin{tabular}{|c|c|c|c|c|c|c|}
\hline Variable & Level & $\mathbf{N}$ (calf) & Positive N (\%) & OR & CI & P-value \\
\hline \multirow[t]{2}{*}{ Season } & Summer & 338 & $14(4.14)$ & 1 & & \multirow[t]{2}{*}{0.07} \\
\hline & Winter & 73 & $7(9.59)$ & 2.45 & $0.95-6.31$ & \\
\hline \multirow{2}{*}{ Age (weeks) } & $\leq 3$ & 215 & $7(3.26)$ & 1 & & \multirow[t]{2}{*}{0.07} \\
\hline & $>3$ & 196 & $14(7.14)$ & 2.28 & & \\
\hline \multirow[t]{3}{*}{ Type of barn } & Closed & 113 & $11(9.73)$ & 1 & & \multirow[t]{3}{*}{0.03} \\
\hline & Partially open & 144 & $6(4.17)$ & 0.40 & $0.14-1.12$ & \\
\hline & Open & 154 & $4(2.60)$ & 0.24 & $0.07-0.79$ & \\
\hline \multirow{3}{*}{$\begin{array}{l}\text { Floor of the calf } \\
\text { area }\end{array}$} & Concrete/slatted & 245 & $10(4.08)$ & 1 & & \multirow[t]{3}{*}{0.04} \\
\hline & Brick & 103 & $10(9.71)$ & 2.52 & $1.01-6.27$ & \\
\hline & Grass/muddy & 63 & $1(1.59)$ & 0.37 & $0.04-3.01$ & \\
\hline \multirow{3}{*}{$\begin{array}{l}\text { Drinking water } \\
\text { supply }\end{array}$} & Surface water & 74 & $1(1.35)$ & 1 & & \multirow[t]{3}{*}{0.05} \\
\hline & Municipal supply & 15 & 0 & - & - & \\
\hline & Tube well & 322 & $20(6.21)$ & 4.83 & $0.63-36.61$ & \\
\hline \multirow{3}{*}{$\begin{array}{l}\text { Separation of calf } \\
\text { from dam }\end{array}$} & $>24$ hours & 243 & $10(4.12)$ & 1 & & \multirow[t]{3}{*}{0.02} \\
\hline & $<24$ hours & 114 & $4(3.51)$ & 0.84 & $0.25-2.76$ & \\
\hline & Immediately after birth & 48 & $7(14.58)$ & 3.97 & $1.43-11.04$ & \\
\hline \multirow{3}{*}{$\begin{array}{l}\text { First colostrum } \\
\text { after birth }\end{array}$} & Within 30 minutes & 221 & $4(1.81)$ & 1 & & \multirow[t]{3}{*}{0.0003} \\
\hline & Within 2 hours & 172 & $17(9.88)$ & 5.94 & $1.96-18.02$ & \\
\hline & Within 2-6 hours & 16 & 0 & - & - & \\
\hline \multirow[t]{3}{*}{ History of calf scour } & No & 112 & $1(0.89)$ & 1 & & \multirow[t]{3}{*}{0.02} \\
\hline & Recovered & 104 & $6(5.77)$ & 6.79 & $0.80-57.43$ & \\
\hline & Yes & 195 & $14(7.18)$ & 8.58 & $1.11-66.19$ & \\
\hline \multirow{3}{*}{ Fecal consistency } & Solid & 184 & $5(2.72)$ & 1 & & \multirow[t]{3}{*}{0.01} \\
\hline & Semi-solid & 75 & $2(2.67)$ & 0.98 & $0.18-5.17$ & \\
\hline & Liquid & 152 & $14(9.21)$ & 3.63 & $1.27-10.32$ & \\
\hline \multirow[t]{3}{*}{ Parity } & $1-2$ & 149 & $2(1.34)$ & 1 & & \multirow[t]{3}{*}{0.01} \\
\hline & $3-4$ & 222 & $17(7.66)$ & 6.09 & $1.38-26.78$ & \\
\hline & $>4$ & 40 & $2(5.00)$ & 3.86 & $0.52-28.36$ & \\
\hline \multirow{3}{*}{$\begin{array}{l}\text { Maximum age } \\
\text { difference between } \\
\text { calves within a calf } \\
\text { pen }\end{array}$} & $>8$ weeks & 204 & $8(3.92)$ & 1 & & \multirow[t]{3}{*}{0.08} \\
\hline & 4-8 weeks & 163 & $8(4.91)$ & 1.26 & $0.46-3.44$ & \\
\hline & $<4$ weeks & 44 & $5(11.36)$ & 3.14 & $0.97-10.11$ & \\
\hline
\end{tabular}

Table 2. Final multilevel multivariable logistic regression model (farm as random effect) showing the significant $(p<0.05)$ association of different farm and animal level factors with the presence of Rota virus in the fecal sample of calves in ELISA.

\begin{tabular}{|c|c|c|c|c|}
\hline Variable & Level & OR & $95 \% \mathrm{CI}$ & P-value \\
\hline \multirow[t]{2}{*}{ Season } & Summer & 1 & & \multirow[t]{2}{*}{0.002} \\
\hline & Winter & 6.04 & $1.92-18.96$ & \\
\hline \multirow[t]{2}{*}{ Age (weeks) } & $\leq 3$ & 1 & & \multirow[t]{2}{*}{0.04} \\
\hline & $>3$ & 2.87 & $1.03-8.01$ & \\
\hline \multirow[t]{3}{*}{ First colostrums after birth } & Within 30 minutes & 1 & & \multirow[t]{3}{*}{$<0.001$} \\
\hline & Within 2 hours & 13.92 & $3.87-50.05$ & \\
\hline & Within 2-6 hours & - & - & \\
\hline \multirow[t]{3}{*}{ Parity } & $1-2$ & 1 & & \\
\hline & $3-4$ & 6.79 & $1.40-32.92$ & 0.01 \\
\hline & $>4$ & 6.61 & $0.75-57.82$ & 0.08 \\
\hline \multirow{3}{*}{$\begin{array}{l}\text { Maximum age difference between calves } \\
\text { within a pen }\end{array}$} & $>8$ weeks & 1 & & \\
\hline & 4-8 weeks & 1.07 & $0.36-3.16$ & 0.90 \\
\hline & $<4$ weeks & 12.27 & $2.61-57.71$ & 0.001 \\
\hline
\end{tabular}




\section{Discussion}

We estimated the overall prevalence of rotavirus infection in the feces of clinically diarrheal or non-diarrheal (with and without history of diarrhea) calves of less than 6 weeks of age. Overall prevalence was observed as $5.11 \%$ where diarrheal calves were more prone to infection $(7.18 \%)$ than non-diarrheal calves $(0.89 \%)$. Among the clinically non-diarrheic calves-the calves having previous history of diarrhea showed significantly higher infection level than those having no history of diarrhea in the past $(5.77 \%$ vs. $0.89 \%, \mathrm{P}$ value $=0.02)$ (Table 1$)$. This result matches with the previous findings of rotaviral infection in different regions of Bangladesh by various researchers. For instance, Samad and Ahmed (1990) reported 12\% and 3\% prevalence in diarrheic and non diarrheic calves, respectively. Similarly, Selim et al., (1991) studied the rotaviral infection in buffalo calves and estimated the overall prevalence as 7\%, and diarrheic and non diarrheic calves as $7.2 \%$ and $6.3 \%$, respectively. Remarkably, the prevalence of this viral infection was found much more higher in other countries around the world than our study, e.g. 11 to $45 \%$ in India (Rai et al., 2011), 15\% in Vietnam (Kyle, 2007), 16.7\% in Japan (Fukai et al., 1998), 17\% in Brazil (Alfieri et al., 2006), 42\% in Britain (Reynolds et al., 1986), 79.9\% in Australia (Izzo et al., 2011). The intra and inter country differences in the prevalence of this infection might have been influenced by different factors that changes between regions including spatial, temporal, management and host related factors as well as by the factors that might vary between studies including study design, sample size, analytical strategy and crucially by the sensitivity of the diagnostic tests used.

This study also provides an inclusive analysis of risk factors responsible for the presence of rotavirus in calf feces in the study area. The odds of detecting rotavirus in calves in $>3$ weeks of age group was higher $(\mathrm{OR}=2.87 ; 95 \% \mathrm{CI}, 1.03-8.01 ; \mathrm{P}=0.04)$ compared to $\leq 3$ weeks age group. Higher susceptibility in $>3$ weeks age calves was also observed by Garcia et al. (2000) who stated highest prevalence in 22-30 days group (44.8\%) in contrast to other groups: 1-7 days (15.6\%), 8-14 days (12.3\%) and 15-21 days (13.2\%). However, the relation of age of calves with the prevalence of rotaviral infection is not consistent as some of the previous studies demonstrated higher frequency (33.77\%) in 8-14 days old age group compared to other age groups: $19.23 \%, 0 \%$ and $11.11 \%$ in 1-7, 15-21, 22-30 days of age, respectively (Ammar et al., 2014). Furthermore, there is evidence that calves develop resistance against rotavirus with progression of age (Tzipori et al., 1981) and usually the clinical outcome is rare in older calves than in one month of age and it is more common in second week of life (Woode and Bridger, 1975; Acres and Babiuk, 1978; Bridger and Pocock, 1986). However, Some strains are able to cause infection in calves at any age (Bridger and Pocock, 1986) and a study from United Kingdom demonstrated the clinical phase of rotavirus in colostrum-deprived and gnotobiotic calves of up to 56 days of age (Woode and Bridger, 1975). To understand the discrepancies in influence of age in the present study with some other previous studies, it is crucial to characterize the strains of the agent responsible in the study area. Furthermore, it is essential to reveal if there is any genetic mutation that might alter the transmission dynamics of the virus.

Season was identified as a vital factor for rotavirus infection in calves of the study area. Calves less than 6 weeks of age if were exposed to winter weather had significantly increased risk (OR=6.04; 95\% CI, 1.92-18.96; $\mathrm{P}=0.002$ ) of rotavirus infection compared to that exposed to summer weather. Higher chance of rotaviral infection in winter was also observed by Ahmed (1990) and Trotz-Williams et al. (2007) where 16.7\% and 31\% prevalence in winter season compared to $9.1 \%$ and $22 \%$ in summer were estimated. Increased risk of rotaviral infection during winter season might be explained as the increased survivability of the virus at low temperature and relative humidity (Brandt et al., 1982; Nourmohammadzadeh et al., 2012; Asadi et al., 2015). Additionally, the titer of IgG concentration in colostrums which had been claimed to act as protective factor against such infection in calves becomes lower in winter compared to other seasons (Gulliksen et al., 2008).

We observed significant relationship between times of first intake of colostrums after birth with rotavirus infection in calves. The odds of having the infection were 13 times higher (95\% CI, 3.87-50.05; $\mathrm{P}=<0.001$ ) when calves were provided colostrums after 30 minutes to 2 hours of birth compared to within 30 minutes. Prior perception is that colostrums carry specific anti-rotaviral immunoglobulins that protects infection of rotavirus and diarrhea (Radostitis et al., 2000). It was found that when colostrums is collected more than 2 hours after calving, the colostral IgG amount declined significantly (Morin et al., 2010), might be because of the dilutional effects and diffusion of IgG into the systemic circulation of dam if colostrums is not milked out or fed to calves as soon as possible after calving. Moreover the delayed intake of colostrums decreases the absorption of intestinal immunoglobulin and fat soluble vitamins (Bellinzoni et al., 1989; Fayer et al., 2000; Bazeley, 2003). Although our results showed more protection in calves when colostrums was taken within 30 minutes of birth in comparison to colostrums intake after 30 minutes to within 2 hours, a linear increase in risk among calves that were provided colostrums between 2-6 hours after birth could not be established because of the absence of positive cases at this level (only 16 calves among 411 belonged to this group). 
We perceived a significant association between parity of dam with rotavirus infection in calves; calves from 3-4 parity was significantly in higher risk $(\mathrm{OR}=6.79)$ compared to their low parity counterpart. Some studies suggested that colostrums of cows in their $3^{\text {rd }}$ or $4^{\text {th }}$ parity or older usually have significantly higher levels of IgG than heifers or $2^{\text {nd }}$ parity cows (Gulliksen et al., 2009) that might influence the infection status in calves. However, this relationship between parity and colostrum IgG amount was not always obvious (Chigerwe et al., 2008). Nevertheless, it was suggested that if the dam has not been dry long enough after calving (minimum 4 weeks); it may lower the IgG level in milk that might be a concern for the high parity cows.

We noted that if the maximum age difference between calves within a pen was less than four weeks, the odds of being infected with rotavirus was higher $(\mathrm{OR}=12.27 ; 95 \% \mathrm{CI}, 2.61-57.71 ; \mathrm{P}=0.001)$ in comparison to more than four weeks group. This phenomenon might be explained as if calves with a more or less similar age are housed together they share the similar risk factors (e.g. feeding utensils) and spread infection more easily within the group. However, group housing for calves less than 30 days of age is not recommended and the number of calves per group also needs to be considered (Gulliksen et al., 2009). In a previous study conducted on the same study population observed that single housing for calves is very rare in the study area (6 out of 210 farmers practiced single housing) (Chowdhury et al., 2017). We did not observe any significant influence of single/group calf housing on being positive to rotavirus infection in the present study, however might be because of very much skewed distribution of the variable. Data regarding number of claves within each house was not collected in the present study that might have incorporated some confounding bias in to the analysis.

Due to hierarchical nature of the data we used random mixed models to evaluate risk factors for the rotavirus infection in calves less than 6 weeks of age. The number of positive samples (21) was far too low to do a powerful multivariable analysis including random effect(s). The final multivariable model contains 5 variables with 108 separate combinations of categories, so many must have no positives at all. This will lead to only high OR's to be significant (see Table 2) and interactions being non-significant.

We also observed a wide confidence interval for some of the estimates in the final model, might be the effect of using this complex statistical model to a low prevalent infection. However, despite all these limitations, to account the clustering effect of farm, it was worth using a complex model in this study. The sensitivity of ELISA in diagnosis of rotavirus was found low (around 44\%) when compared with qRT-PCR in previous studies (Izzo et al., 2012). Though we did not evaluate the sensitivity of ELISA in our study set up, however it might be stated that if the sensitivity was not optimum it might have induced some misclassification bias (false negative) in to the study.

\section{Conclusions}

The present study indicates that the circulation of rotavirus in calves in Bangladesh is not very uncommon. We explored a number of risk factors probably contributing to the transmission dynamics of the virus in the study area. Particularly, winter season, more than 3 weeks of age, late colostrums feeding after birth, calves from $3^{\text {rd }}$ and $4^{\text {th }}$ parity and less age difference between the calves within a pen were associated with increased odds of presence of rotavirus in calf feces. Information regarding the disease burden and its associated risk factors might benefit the dairy farmers through targeted allocation of resources for controlling the situation. However, identification of circulating genotypes is essential for development of more specific preventive strategies and future immunization approach. Finally, along with rotavirus, a comprehensive study on neonatal calf diarrhea attributable to other potential enteropathogens is needed to be executed to apply a coordinated control program efficiently to reduce resulted calf mortality in the study area.

\section{Acknowledgements}

This work was supported by Higher Education Quality Enhancement Project (CP: 3220) of the University Grants Commission of Bangladesh.

\section{Conflict of interest}

None to declare.

\section{References}

Acres S and LA Babiuk, 1978. Studies on rotaviral antibody in bovine serum and lacteal secretions, using radioimmunoassay. J. Am. Vet. Med. Assoc., 173: 555-559.

Al-Robaiee IA and MI Al-Farwachi, 2013. Prevalence of rotaviral infection in diarrheic neonatal calves in Mosul city, Iraq. Vet. World, 6: 538-540. 
Alam MN, MM Alam, N Nahar and N Kobayashi, 2013. Molecular epidemiological studies on rotavirus infection causing severe diarrhea in human, animals and poultry. Bangladesh J. Vet. Med., 9: 167-175.

Alfieri AA, ME Parazzi, E Takiuchi and KC Médici, 2006. Frequency of group A rotavirus in diarrhoeic calves in Brazilian cattle herds, 1998-2002. Trop. Anim. Health Prod.,38: 521-526.

Ammar SSM, K Mokhtaria, BB Tahar, AA Amar, BA Redha, B Yuva, HS Mohamed, N Abdellatif and B Laid, 2014. Prevalence of rotavirus (GARV) and coronavirus (BCoV) associated with neonatal diarrhea in calves in western Algeria. Asian Pac. J. Trop. Biomed., 4:318-322.

Anh PH, JJ Carrique-Mas, N Van, N Cuong, NT Hoa, NL Anh, VB Hien, MA Rabaa, J Farrar, S Baker and JE Bryant, 2014. The prevalence and genetic diversity of group A rotaviruses on pig farms in the Mekong Delta region of Vietnam. Vet. Microbiol., 170: 258-265.

Asadi AH, M Baghinezhad and H Asadi, 2015. Neonatal calf diarrhea induced by rotavirus and coronavirus. Int. J. Biosci., 6: 230-236.

Basera SS, R Singh, N Vaid, K Sharma, S Chakravarti, and Y Malik, 2010. Detection of rotavirus infection in bovine calves by RNA-PAGE and RT-PCR. Indian J. Virol., 21: 144-147.

Bazeley K, 2003. Investigation of diarrhoea in the neonatal calf. In Pract., 25: 152-159.

Bellinzoni R, J Blackhall, N Baro, N Auza, N Mattion, A Casaro, J La Torre, E Scodeller, 1989. Efficacy of an inactivated oil-adjuvanted rotavirus vaccine in the control of calf diarrhoea in beef herds in Argentina. Vaccine, 7: 263-268.

Bendali F, H Bichet, F Schelcher and M Sanaa, 1999. Pattern of diarrhoea in newborn beef calves in south-west France. Vet. Res., 30: 61-74.

Brandt C, H Kim, W Rodriguez, J Arrobio, B Jeffries and R Parrott, 1982. Rotavirus gastroenteritis and weather. J. Clin. Microbiol., 16: 478-482.

Bridger J and D Pocock, 1986. Variation in virulence of bovine rotaviruses. J. Hyg., 96: 257-264.

Chauhan R and N Singh, 1996. Epidemiology of rotavirus infection in calves in India. Int. J. Anim. Sci., 11: 221-223.

Chigerwe M, JW Tyler, LG Schultz, JR Middleton, BJ Steevens and JN Spain, 2008. Effect of colostrum administration by use of oroesophageal intubation on serum IgG concentrations in Holstein bull calves. Am. J. Vet. Res., 69: 1158-1163.

Chowdhury S, SR Barua, TM Rakib, MM Rahman, T Ferdushy, MA Hossain, MS Islam and M Masuduzzaman, 2017. Survey of calf management and hygiene practices adopted in commercial dairy farms in Chittagong, Bangladesh. Adv. Anim. Vet. Sci., 5: 16-22.

De Rycke J, S Bernard, J Laporte, M Naciri, M Popoff and A Rodolakis, 1986. Prevalence of various enteropathogens in the feces of diarrheic and healthy calves. Ann. Rech. Vet., 17: 159-168.

De Verd Er, 2006. Infektionspanoramat vid diarreer hos svenska kalvar. Svensk Veterinartidning, 58: 29.

Dhama K, R Chauhan, M Mahendran and S Malik, 2009. Rotavirus diarrhea in bovines and other domestic animals. Vet. Res. Commun., 33: 1-23.

Fayer R, U Morgan and SJ Upton, 2000. Epidemiology of Cryptosporidium: transmission, detection and identification. Int. J.Parasitol., 30: 1305-1322.

Fukai K, T Sakai and H Kamata, 1998. Distribution of G serotypes and P genotypes of bovine group A rotavirus isolated in Japan. Aus. Vet. J., 76: 418-422.

Gachanja E, J Buza and P Petrucka, 2015. Prevalence of Group A Rotavirus in Piglets in a Peri-Urban Setting of Arusha, Tanzania. J. Biosci. Med., 4: 37-44.

Garcıa A, J Ruiz-Santa-Quiteria, J Orden, D Cid, R Sanz, M Gómez-Bautista and R De la Fuente, 2000. Rotavirus and concurrent infections with other enteropathogens in neonatal diarrheic dairy calves in Spain. Comp. Immunol. Microbiol. Infect. Dis., 23: 175-183.

Gulliksen S, K Lie, L Sølverød and O Østerås, 2008. Risk factors associated with colostrum quality in Norwegian dairy cows. J. Dairy Sci., 91: 704-712.

Gulliksen SM, KI Lie, T Løken and O Østerås, 2009. Calf mortality in Norwegian dairy herds. J. Dairy Sci., 92: 2782-2795.

Izzo M, P Kirkland, X Gu, Y Lele, A Gunn and J House, 2012. Comparison of three diagnostic techniques for detection of rotavirus and coronavirus in calf faeces in Australia. Aus. Vet. J., 90: 122-129.

Izzo M, P Kirkland, V Mohler, N Perkins, A Gunn and J House, 2011. Prevalence of major enteric pathogens in Australian dairy calves with diarrhoea. Aus. Vet. J., 89: 167-173.

Jindal S, N Maiti and M Oberoi, 2000. Genomic diversity and prevalence of Rotavirus in cow and buffalo calves in northern India. Rev. Sci. Tech. (International Office of Epizootics), 19: 871-876. 
Kyle H, 2007. Infection of rotavirus in dairy calves in south Vietnam. Department of Clinical Sciences. Swedish University of Agricultural Sciences, Uppsala, Sweden, 1-19.

Malik YS, N Kumar, K Sharma, R Sharma, HB Kumar, K Anupamlal, S Kumari, S Shukla and K Chandrashekar, 2013. Epidemiology and genetic diversity of rotavirus strains associated with acute gastroenteritis in bovine, porcine, poultry and human population of Madhya Pradesh, Central India, 20042008. Adv. Anim. Vet. Sci., 1 (4): 111 - 115.

Martella V, K Bányai, J Matthijnssens, C Buonavoglia and M Ciarlet, 2010. Zoonotic aspects of rotaviruses. Vet. Microbiol., 140: 246-255.

Matthijnssens J and U Desselberger, 2012. Genome diversity and evolution of rotaviruses. Genome Plasticity and Infectious Diseases. Am. Soc.Microbiol., 13: 214-241.

Matthijnssens J, O Nakagomi, CD Kirkwood, M Ciarlet, U Desselberger and MV Ranst, 2012. Group A rotavirus universal mass vaccination: how and to what extent will selective pressure influence prevalence of rotavirus genotypes? Expert review of vaccines, 11:1347-1354.

Morin DE, SV Nelson, ED Reid, DW Nagy, GE Dahl and PD Constable, 2010. Effect of colostral volume, interval between calving and first milking, and photoperiod on colostral IgG concentrations in dairy cows. J. Am. Vet. Med. Assoc., 237: 420-428.

Nataraju S, U Chattopadhyay and T Krishnan, 2009. A study on the possibility of zoonotic infection in rotaviral diarrhoea among calves and buffalo calves in and around Kolkata, India. Eur. Rev. Med. Pharmacol. Sci., 13: 7-11.

Nourmohammadzadeh F, Y Davoudi, G Abdollahpour and A Nouri, 2012. The prevalence of rotavirus in neonatal calf diarrhoea, using electron microscopic examination. Comp. Clin. Pathol., 21: 1231-1234.

Radostitis O, C Gay, D Blood and K Hinchcliff, 2000. Veterinary medicine 9th ed. WB Sauders. London.

Rai R, A Hansha, S Rai, B Singh, H Kumar, A Singh, T Damodaran and K Dhama, 2011. Prevalence of rota and coronavirus infections in calves of Barabanki and Raebareli districts of Uttar Pradesh. Indian J. Vet. Pathol., 35: 73-74.

Reynolds D, J Morgan, N Chanter, P Jones, J Bridger, T Debney and K Bunch, 1986. Microbiology of calf diarrhoea in southern Britain. Vet. Rec.,119: 34-39.

Samad MW and MA Ahmed, 1990. Epidemiological investigation of rotavirus infection in buffalo calves in Bangladesh. In, Proceeding of Domestic Buffalo Production in Asia, Mymensingh, Bangladesh, 195-200.

Selim S, K Aziz, A Sarker and H Rahman, 1991. Rotavirus infection in calves in Bangladesh. Vet. Res. Commun., 15: 327-333.

Steele A, A Geyer and G Gerdes, 2004. Rotavirus infections. Infectious Diseases of Livestock, Oxford University Press, Southern Africa, 1256-1264.

Straw B, JJ Zimmerman, S D’Allaire and DJ Taylor, 2006. Eds. Diseases of Swine. Blackwell publishing.

Suresh T, R Rai, K Dhama, S Rai, P Sawant and A Sharma, 2011. Pathology of rotavirus infection in calves and detection of viral antigen by ELISA and FAT. Indian J.Vet. Pathol., 35: 1-3.

Tzipori S, 1985. The relative importance of enteric pathogens affecting neonates of domestic animals. Adv. Vet. Sci. Comp. Med., 29: 103-206.

Woode G and JC Bridger, 1975. Viral enteritis of calves. Vet. Rec., 96: 85-88.

Zimmerman J, D Benfield, M Murtaugh, F Osorio, G Stevenson, and M Torremorell, 2006. Porcine reproductive and respiratory syndrome virus (porcine arterivirus). Diseases of swine, 387-418. 